\title{
Noise characteristics of GPS time series and their influence on velocity uncertainties
}

\author{
Jagat Dwipendra Ray ${ }^{1,2}$, M Sithartha Muthu $\operatorname{Vijayan}^{3, *}$ (®) and Ashok Kumar ${ }^{1}$ \\ ${ }^{1}$ Department of Physics, Tezpur University, Tezpur, Assam, India. \\ ${ }^{2}$ Department of Physics, NIT Nagaland, Dimapur, India. \\ ${ }^{3}$ Multi-Scale Modelling Programme (MSMP), CSIR Fourth Paradigm Institute [CSIR 4PI], \\ Bengaluru, Karnataka, India. \\ *Corresponding author.e-mail: vijayan@csir4pi.in
}

MS received 1 May 2018; revised 19 December 2018; accepted 1 March 2019; published online 31 May 2019

Accurate geodetic crustal deformation estimates with realistic uncertainties are essential to constrain geophysical models. A selection of appropriate noise model in geodetic data processing based on the characteristics of the geodetic time series being studied is the key to achieving realistic uncertainties. In this study, we report noise characteristics of a 12-yr long global positioning system (GPS) geodetic time series (2002-2013) obtained from 22 continuous mode GPS stations situated in north-east India, Nepal and Bhutan Himalayas which are one of the most complex tectonic regimes influenced by the largest hydrological loading and impacted with a load of the largest inland glaciers. A comparison of the maximum log likelihood estimates of three different noise models - (i) white plus power law (WPL), (ii) white plus flicker law (WFL) and (iii) white plus random walk noise - adopted to process the GPS time series reveals that among the three models, $\sim 74 \%$ of the time series can be better described either by WPL or WFL model. The results further showed that the horizontals in Nepal Himalayas and verticals in north-east India are highly correlated with time. The impact analysis of noise models on velocity estimation shows that the conventional way of assuming time uncorrelated noise models (white noise) for constraining the crustal deformation of this region severely underestimates rate uncertainty up to 14 times. Such simplistic assumption, being adopted in many geodetic crustal deformation studies, will completely mislead the geophysical interpretations and has the potential danger of identifying any inter/intra-plate tectonic quiescence as active tectonic deformation. Furthermore, the analysis on the effect of the time span of observations on velocity uncertainties suggests $3 \mathrm{yr}$ of continuous observations as a minimum requirement to estimate the horizontal velocities with realistic uncertainties for constraining the tectonics of this region.

Keywords. Noise; GPS; time series; maximum likelihood estimation; velocity; crustal deformation; error analysis.

\section{Introduction}

Global positioning system (GPS) measurements with its millimetre-level accuracy have been widely used to study the deformation of the Earth's crust. Secular deformation rates (GPS site velocities) are estimated by fitting a linear trend to continuous GPS position time series. The estimates of

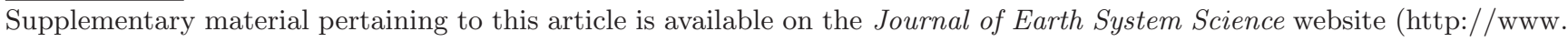
ias.ac.in/Journals/Journal_of_Earth_System_Science). 
deformation rates, in common, are based on an assumption that measurements are not correlated with time (white noise). Such oversimplification leads to the underestimation of rate errors, and the underestimated rate errors critically affect the interpretation and modelling of geophysical signals (Beavan 2005). GPS site velocities are found to be affected by various sources which include reference frame errors (Argus et al. 1999), seasonal signals (Blewitt and Lavallée 2002), position offsets (Williams 2003) and antenna phase centre model errors (Cardellach et al. 2007; Steigenberger et al. 2009). Several studies (e.g., Langbein and Johnson 1997; Zhang et al. 1997; Mao et al. 1999; Williams et al. 2004; Beavan 2005) revealed that geodetic measurements of position or distance changes are temporally correlated.

The underlying geophysical phenomena which give rise to temporal correlation in geodetic measurements can be approximated by a power law (PL) of the form

$$
P(f)=P_{0}\left(\frac{f}{f_{0}}\right)^{k}
$$

where $k$ is the spectral index, $P_{o}$ and $f_{o}$ are normalising constants, and $f$ is the temporal frequency (e.g., Mandelbrot and Van Ness 1968). The typical range of the spectral index $k$ is $[-3,1]$ (e.g., Agnew 1992). The stochastic processes falling within this range are categorised into stationary and non-stationary processes. The processes with a spectral index within -1 and 1 , including the special case of uncorrelated white noise $(k=0)$ are called fractal white noise or fractal Gaussian noise. The processes $(-3<k<-1)$ including the special case of random walk (RW) noise $(k=-2)$ are called fractal RW or fractal Brownian motion (brown noise). There is another special case with $k=-1$, which is commonly observed in various dynamical processes, and is represented as flicker (FL) noise. The physical mechanism giving rise to the temporal correlation implied by FL noise has not been identified properly but a major component is related with the true physical site motion generated by surface loading due to hydrology and atmospheric pressure (Blewitt and Lavallée 2002). A lower value of spectral index implies a more correlated process and a more relative power at lower frequencies (Amiri-Simkooei et al. 2007). Measurements from continuously recording strainmeters and tiltmeters at the Ida and Cecil Green Pinon
Flat Observatory (PFO) from Southern California, USA show a PL process that is close to RW (Wyatt 1982, 1989). A RW like power spectrum, mostly caused by monument instability, has also been observed by Langbein et al. (1987). Later studies by Zhang et al. (1997) on regional network and Mao et al. (1999) on global GPS solutions revealed that noise in the continuous GPS position time series was best characterised by either fractal white noise or a combination of FL plus white noise.

Williams et al. (2004) did a comprehensive analysis of both global and regional GPS network using maximum log likelihood estimation and observed that, for the global distributed site, noise can be best described by white plus flicker law (WFL) noise. They, also, observed that both the noise components show latitude dependency. An evaluation of the continuous GPS time series from Southern California and Southern Nevada network using Maximum Likelihood Estimation (MLE) revealed that the background noise model for many time series can be described by either (i) a sum of FL and random-walk noise or (ii) as a PL noise model that represents an average of the FL and random-walk noise (Langbein 2008). The effects of time correlation in a weekly GPS position time series on velocity estimates was studied by Santamaría-Gómez et al. (2011) using 275 globally distributed stations spanning 2.5-13 yr. In this study, Santamaría-Gómez et al. (2011) found that the noise characteristics of the GPS time series can be represented by a combination of variable white noise and PL noise models and demonstrated that correlated noise content is dependent on time series length. Wang et al. (2012) analysed noise characteristics of the GPS time series of the Crustal Movement Observation Network of China (CMONOC) for the unfiltered and filtered solutions in terms of PL plus white noise model and observed that the main coloured noise for the unfiltered solutions of CMONOC continuous GPS sites is a FL process, with a mean spectral index of -1 and for filtered solution general PL.

The temporal correlation in the GPS coordinate time series therefore should be accounted so that a realistic estimation of uncertainties becomes possible. In the absence of noise characteristics of the GPS time series observed in the Indian and the Himalayan region, several studies carried out to estimate the ongoing crustal deformation in this region (e.g., Banerjee and Bürgmann 2002; 
Bettinelli et al. 2006; Mahesh et al. 2012) adopted noise characteristics derived either from the error analyses of global networks or from the regional networks in other parts of the world. For example, Banerjee and Bürgmann (2002) scaled the formally computed velocity uncertainties by a factor of 2 to accommodate the time correlated noise. Bettinelli et al. (2006) increased the uncertainties by a factor of 3 to account for the effect of time correlated noise. Mahesh et al. (2012) estimated station velocity uncertainties by using site-specific white noise and an assumed RW noise of $0.75 \mathrm{~mm} / \mathrm{yr}^{1 / 2}$. Later, Ader et al. (2012) obtained secular GPS velocities by modelling the noise in the GPS position time series as a combination of white and coloured noise.

The Indian subcontinent includes tectonically complex regimes of the world like north-east India, Nepal and Bhutan Himalayas which are also influenced by one of the largest hydrological loading, next to Amazon and Congo basin, in addition to the load of the largest inland glaciers. Hence, it is critical to identify the noise characteristics of this region for estimating the realistic secular deformation of the crust. Considering the importance, we analyse a 12-yr long GPS geodetic time series (2002-2013) obtained from 22 GPS stations situated in north-east India, Nepal and Bhutan Himalayas together to obtain the noise characteristics and identify the noise model suitable to the region. We also report the minimum period of observation required to obtain the robust secular crustal-velocities of this region which suffers large seasonal deformation (Ray 2016) by analysing the impact of observational time span on estimating the secular crustal deformation.

\section{Data and methodology}

\subsection{GPS data and processing}

In this study, we have used GPS data from 22 GPS stations from north-east India, Nepal and Bhutan Himalayas observed continuously for a 12-yr period from 2002 to 2013 (figure 1 and table 1). Prior to processing, the data were qualitychecked using the translation, editing and quality check software (TEQC) developed by UNAVCO (Estey and Meertens 1999). We discarded data having less than $12 \mathrm{~h}$ of observation. The data were processed using GAMIT/GLOBK software version 10.4 (Herring et al. 2010a, b). A linear combination of L1 and L2 signals was used to eliminate the delays induced by first-order ionospheric refraction. Second- and third-order refraction-induced signal delays also have been taken into account

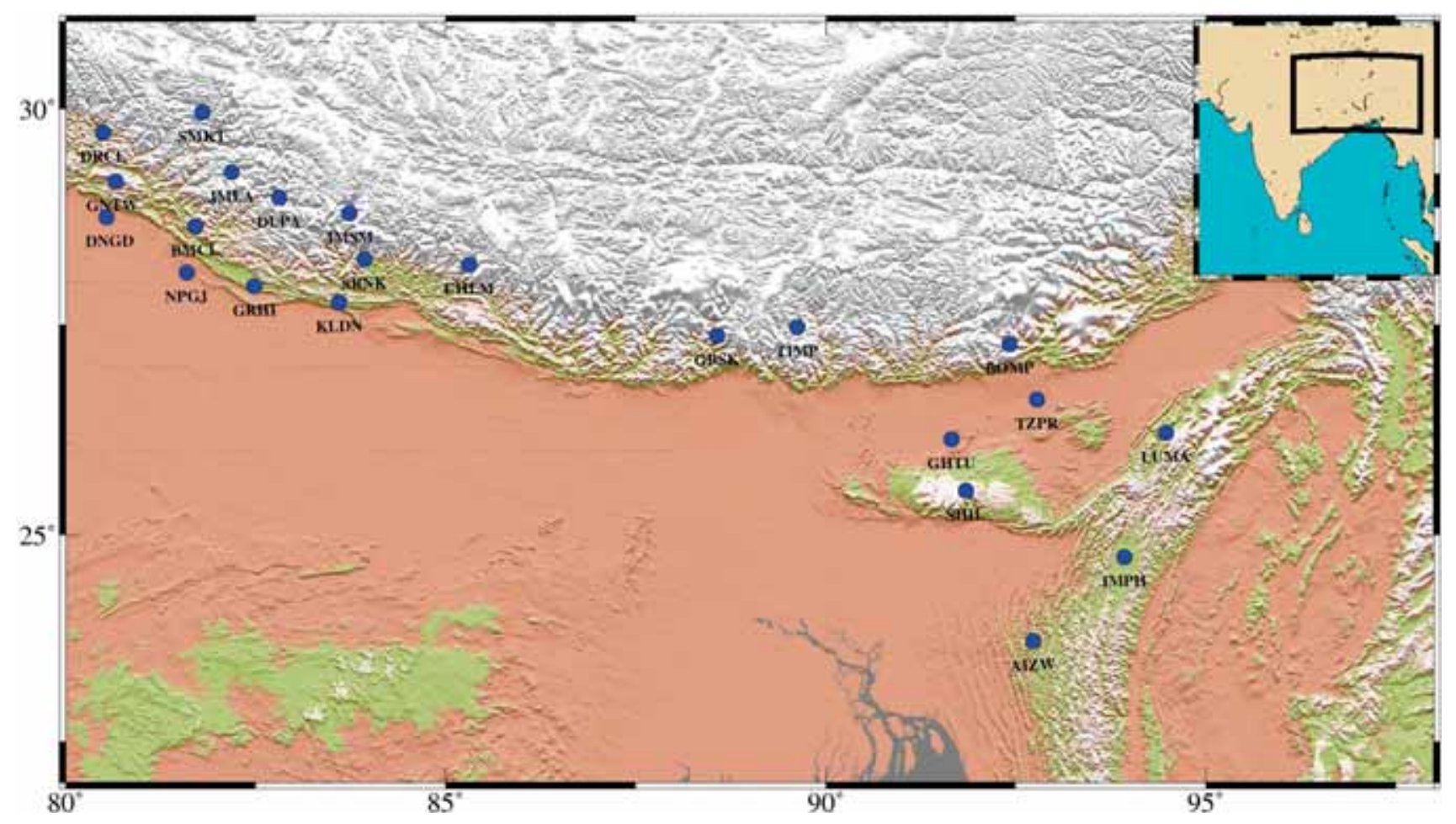

Figure 1. Location of the GPS observations used in this study. Inset shows the study area (marked by rectangle) in Indian subcontinent. 


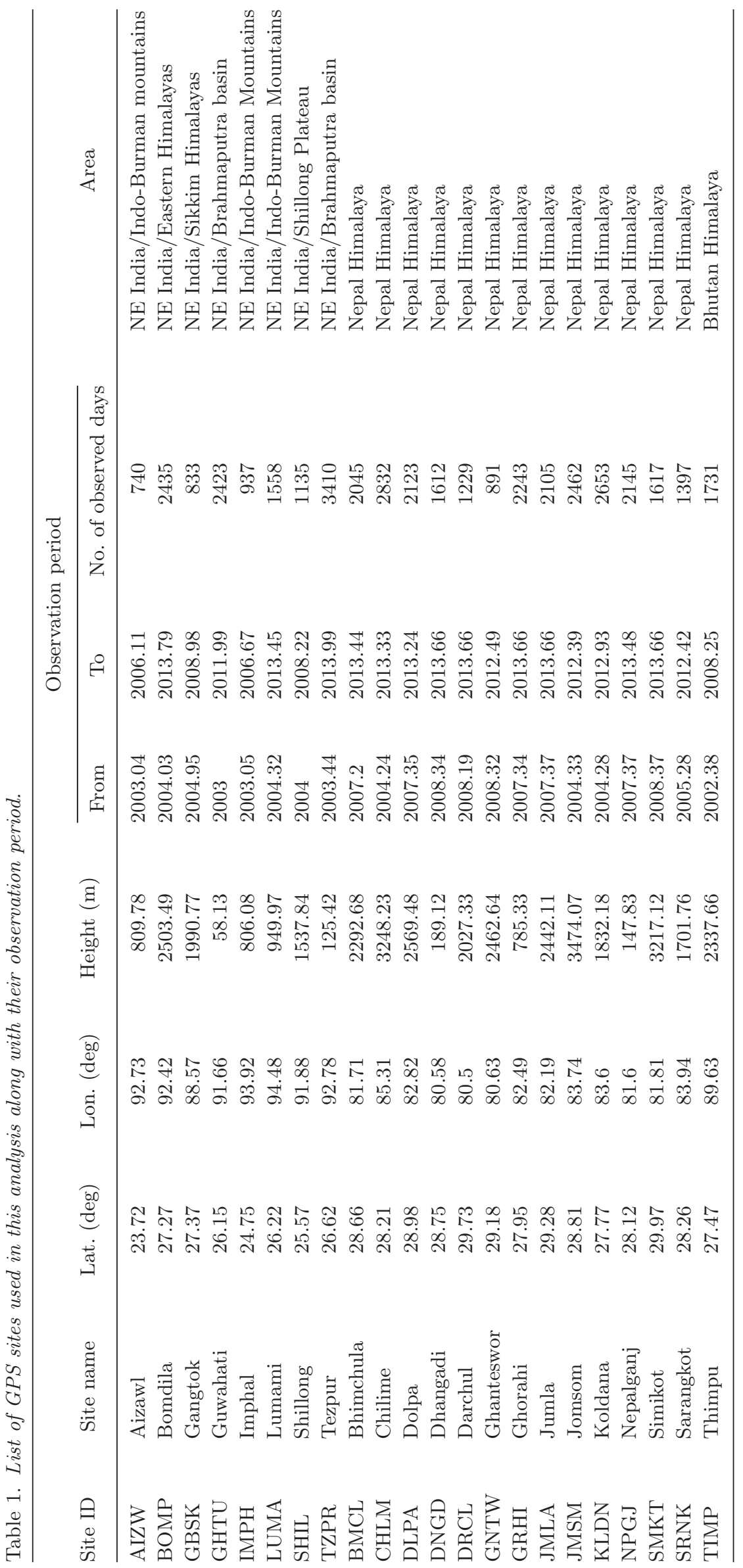


by using daily ionosphere map exchange format (IONEX) files, which are global ionospheric maps of vertical total electron content distributed by the Centre for Orbit Determination in Europe (CODE) (Schaer et al. 1998). For each station, the zenith tropospheric delay was taken into account by estimating it for every $2 \mathrm{~h}$ using piecewise linear function. Vienna mapping function (VMF1) was used in the estimation of tropospheric delay (Kouba 2008) and adopted a priori delay estimates from the global pressure and temperature model (Böhm et al. 2007). We used the atmospheric loading model (Tregoning and Van Dam 2005) to account for the non-tidal atmospheric loading. The ocean tidal loading induced deformation has been corrected by applying the ocean tide loading model (FES 2004) (Lyard et al. 2006). We combined the daily loosely constrained solution from GAMIT with global files generated by MIT (ftp://lox.ucsd.edu/pub/hfiles/) in order to define the reference frame using GLORG, imposing generalised constraints on the frame-defining sites while estimating translation and rotation. The time series of site coordinates are estimated in ITRF08 (Altamimi et al. 2011). Offsets due to co-seismic, receiver and antenna change have been corrected. The outliers were removed from the times series (figure $2 \mathrm{a}-\mathrm{c}$ ). The outlier free time series were detrended by removing the secular trend. The detrended time series consist of all types of noises, including the seasonality (figure $2 \mathrm{a}-\mathrm{c}$ ), which were then used to study the noise characteristics. We applied MLE to investigate the noise characteristics including the time-correlated noise in the GPS time series.

\subsection{Maximum likelihood estimation}

We used the create and analysis time series (CATS) MLE code developed by Williams (2008) to investigate the background noise model in the time series. In this analysis, we assumed that the time series

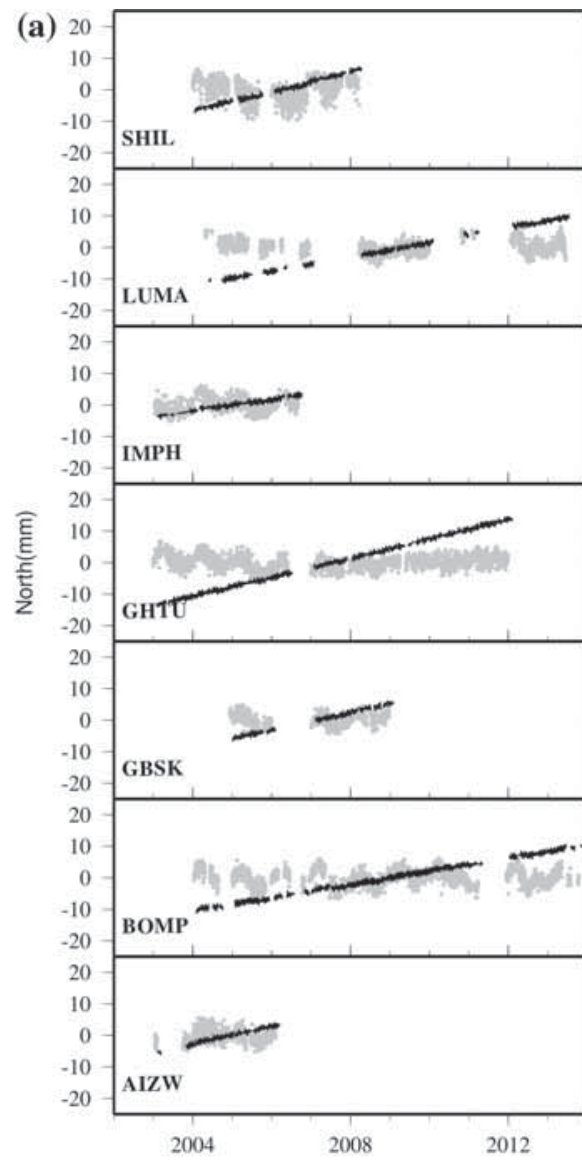

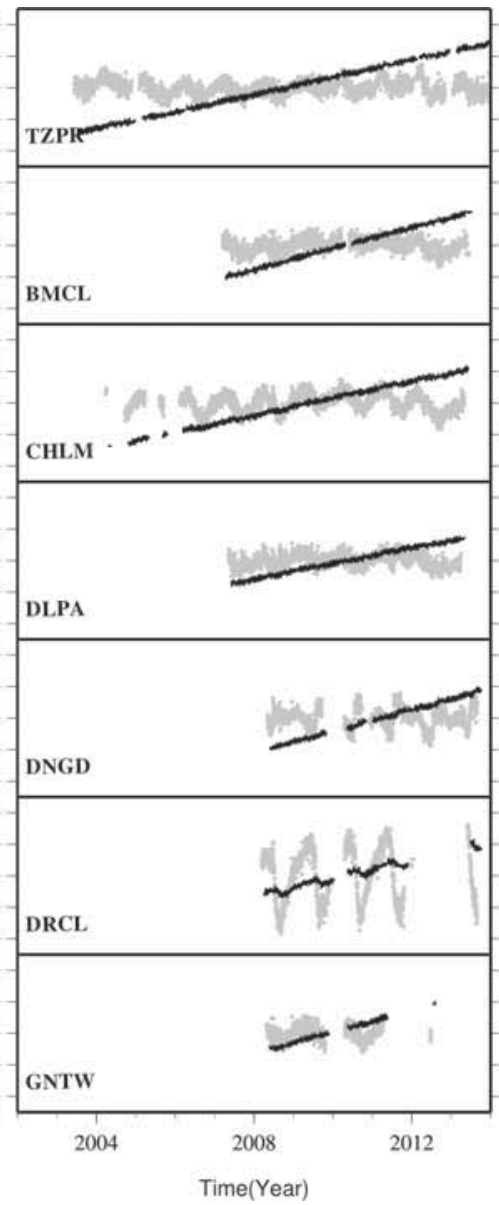

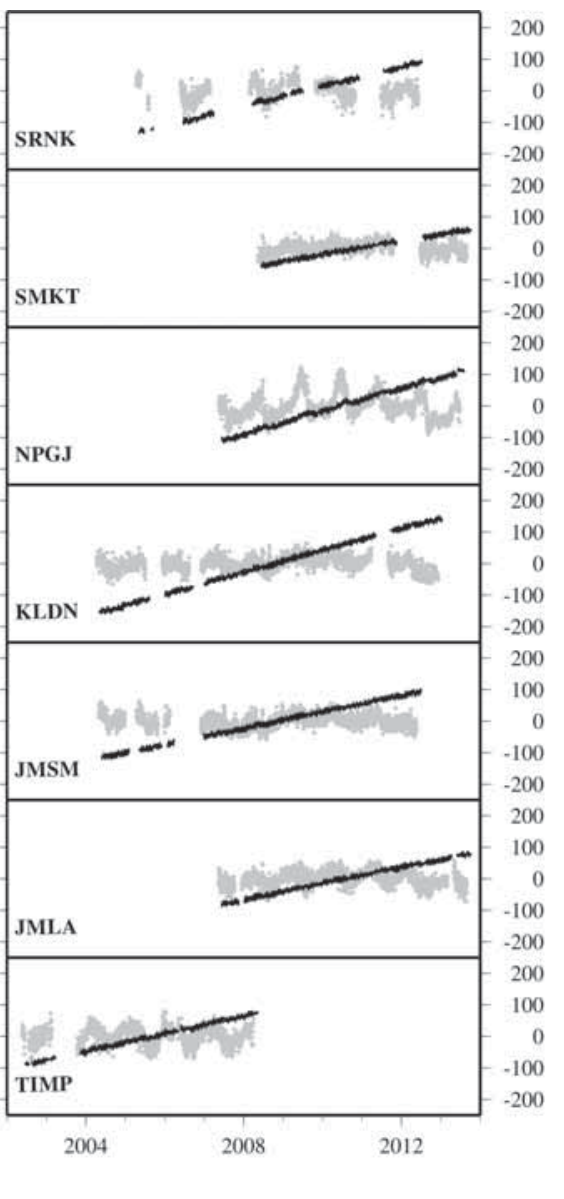

Figure 2. (a) Position time series of GPS stations (north component) used in the study along with secular trend (black) and detrended time series (grey); detrended time series show the seasonal oscillations. (b) East component and (c) up component. 

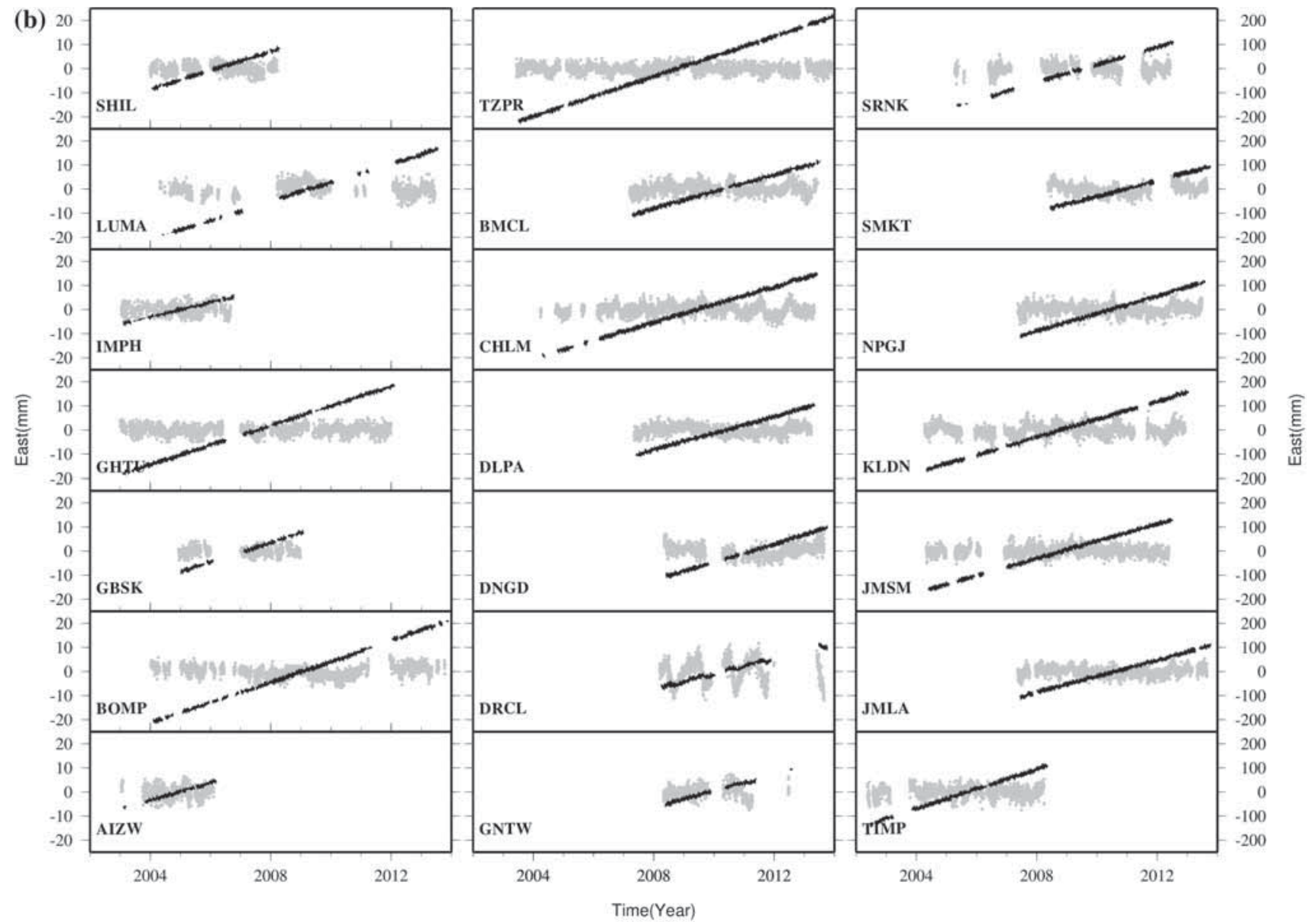

Figure 2. (Continued.)

$X=\left\{x_{n}, t_{n}\right\}$ where $n=1$ to $N$ is combination of two noise sources, white noise $\left(a_{w}\right)$ and PL noise $\left(b_{k}\right)$. Then, the covariance matrix of the observation $(C)$ can be written as

$$
C=a_{\mathrm{w}}^{2}+b_{\mathrm{k}}^{2} \text {. }
$$

To estimate the noise using MLE, the probability function has been maximised by adjusting the data covariance matrix:

$\operatorname{lik}(\hat{v}, C) \frac{1}{(2 \pi)^{N / 2}(\operatorname{det} C)^{1 / 2}} \exp \left(-0.5 \hat{v}^{\mathrm{T}} C^{-1} \hat{v}\right)$.

Taking natural logarithm

$$
\begin{aligned}
\mathrm{MLE} & =\ln [\operatorname{lik}(\hat{v}, C)] \\
= & -\frac{1}{2}\left[\ln (\operatorname{det} C)+\hat{v}^{\mathrm{T}} C^{-1} \hat{v}+N \ln (2 \pi)\right],
\end{aligned}
$$

where $\ln$ is the natural logarithm, $N$ is the number of observations and $v$ is the postfit residual from the linear model applied to the time series (Williams et al. 2004).

\section{Results and discussion}

We used MLE to characterise the noise components in the time series following the studies of Zhang et al. (1997), Mao et al. (1999), Williams et al. (2004) and Wang et al. (2012). In this analysis, we confined ourselves to PL noise only, although other complex noise might exist in the GPS time series (Langbein 2008). First, we tested whether white plus power law (WPL) noise model fit the data better than WN model. We used maximum log-likelihood (MLL) ratio test statistic (Kendall and Stuart 1979) $\Lambda=\exp$ [MLL1-MLL2] to do the test, where 1 is $\mathrm{WN}$ only model and 2 is the WPL noise model. We carried out a null hypothesis test considering WN as the null hypothesis which describes the time series better and tested against an alternative hypothesis, i.e., the WPL. Null hypothesis will be accepted only if $\Lambda$ is close to unity; otherwise, it will be rejected in favour of the coloured noise model (WPL). The MLL values along with $\Lambda$ for the time series are given in table 2 . It is observed that $\Lambda$ values for every site 

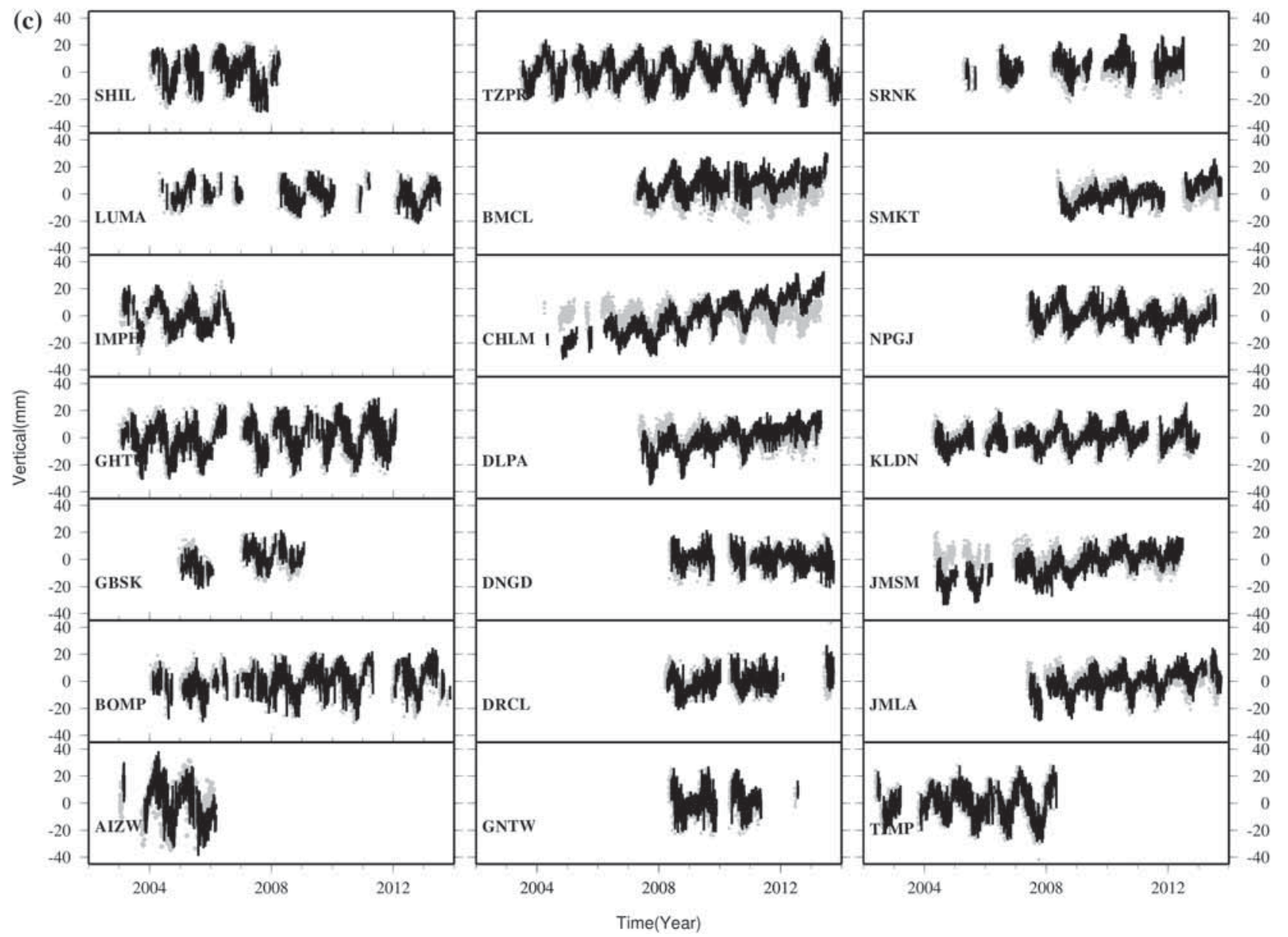

Figure 2. (Continued.)

are zero and hence, we reject the null hypothesis (i.e., WN) in favour of the alternative WPL noise model. The MLL test support for the case that the GPS time series in north-east India, Nepal and Bhutan Himalaya can be better described by the WPL noise model. The spectral index of the time series has been provided in table 2. Median and standard deviation of the estimated spectral index in the time series are $-1.19 \pm 0.23$ (north), $-1.15 \pm 0.21$ (east) and $-1.04 \pm 0.19$ (vertical). It is observed from the median values that spectral indices are mostly described by WPL or WFN. We provide a detailed comparison of the noise models (amplitudes of noise obtained by considering the WN, WFL, WPL and white plus random walk noise (WRN) models pertaining to each time series in the Supplementary material - tables S1-S4).

\subsection{Comparison of noise models}

After rejecting the null hypothesis using the MLL ratio test in favour of WPL, we in this section compare the likelihood values of WPL noise model with two other special PL noise models, viz., (i) WFL and (ii) WRN. In special cases, when $k=-1$, the noise model is termed as FL, and, when $k=-2$, the noise model is termed as RW; otherwise, it is termed as PL noise (Langbein 2012). The likelihood values obtained from the MLE analysis give the degree of coherence between original data and a priori chosen noise model. The higher the values of MLL, the better the model (Langbein 2004). The difference between the MLL values ( $\delta \mathrm{ML}$ ) can be used as a factor to determine the statistical superiority of one noise model over the other (Langbein 2004; Beavan 2005; Williams and Willis 2006; Santamaría-Gómez et al. 2011; Wang et al. 2012). Langbein (2004) used Monte Carlo simulations and showed that the confidence level of rejecting the lower model with $95 \%$ confidence is $\delta \mathrm{ML}>2.8$. Beavan (2005) assumed that $\delta \mathrm{ML}$ greater than 1.92 was significant at the $95 \%$ confidence level. Williams and Willis (2006) got the $\delta$ ML value between 2.9 and 3 for one degree of freedom difference at a $95 \%$ confidence level. In this analysis, we take $\delta \mathrm{ML}>3$ as the criteria 
Table 2. MLL values and $\Lambda$-statistic for every component of time series.

\begin{tabular}{|c|c|c|c|c|c|}
\hline \multirow[b]{2}{*}{ Site code } & \multirow[b]{2}{*}{ Component } & \multicolumn{2}{|c|}{ Max log-likelihood } & \multirow{2}{*}{$\begin{array}{c}\Lambda \text {-statistic } \\
\text { WPL vs. WN }\end{array}$} & \multirow{2}{*}{$\begin{array}{c}\text { Spectra } \\
\text { index }\end{array}$} \\
\hline & & WN & WPL & & \\
\hline \multirow[t]{3}{*}{ AIZW } & North & -1479.43 & -1357.31 & 0 & -1.02 \\
\hline & East & -1629.64 & -1565.18 & 0 & -0.83 \\
\hline & Vertical & -2674.09 & -2598.30 & 0 & -0.98 \\
\hline \multirow[t]{3}{*}{ BOMP } & North & -5083.13 & -4195.32 & 0 & -1.36 \\
\hline & East & -5192.4 & -4259.70 & 0 & -1.24 \\
\hline & Vertical & -8090.12 & -7694.49 & 0 & -1.1 \\
\hline \multirow[t]{3}{*}{ GBSK } & North & -1550.84 & -1399.92 & 0 & -1.26 \\
\hline & East & -1484.00 & -1420.00 & 0 & -0.78 \\
\hline & Vertical & -2573.36 & -2495.68 & 0 & -0.73 \\
\hline \multirow[t]{3}{*}{ GHTU } & North & -5004.56 & -4284.31 & 0 & -1.21 \\
\hline & East & -4502.86 & -4338.57 & 0 & -1.02 \\
\hline & Vertical & -8310.1 & -8006.53 & 0 & -1.07 \\
\hline \multirow[t]{3}{*}{ IMPH } & North & -1908.93 & -1643.80 & 0 & -1.19 \\
\hline & East & -1888.3 & -1841.86 & 0 & -0.97 \\
\hline & Vertical & -2996.73 & -2868.09 & 0 & -1.18 \\
\hline \multirow[t]{3}{*}{ LUMA } & North & -3151.02 & -2647.11 & 0 & -1.44 \\
\hline & East & -3471.53 & -2938.51 & 0 & -1.5 \\
\hline & Vertical & -4928.13 & -4630.88 & 0 & -1.36 \\
\hline \multirow[t]{3}{*}{ SHIL } & North & -2860.00 & -2439.94 & 0 & -0.88 \\
\hline & East & -2174.00 & -2065.98 & 0 & -0.83 \\
\hline & Vertical & -3945.21 & -3753.70 & 0 & -0.76 \\
\hline \multirow[t]{3}{*}{ TZPR } & North & -6751.16 & -5800.01 & 0 & -1.23 \\
\hline & East & -6162.53 & -5846.45 & 0 & -0.94 \\
\hline & Vertical & $-10,927.45$ & $-10,381.61$ & 0 & -1.14 \\
\hline \multirow[t]{3}{*}{ BMCL } & North & -4131.16 & -3606.43 & 0 & -1.04 \\
\hline & East & -4190.35 & -3797.77 & 0 & -1.37 \\
\hline & Vertical & -6520.72 & -6306.53 & 0 & -1.08 \\
\hline \multirow[t]{3}{*}{ CHLM } & North & -5895.41 & -4518.01 & 0 & -1.13 \\
\hline & East & -5727.04 & -5114.27 & 0 & -1.14 \\
\hline & Vertical & -8466.26 & -7866.20 & 0 & -1.16 \\
\hline \multirow[t]{3}{*}{ DLPA } & North & -4287.15 & -3662.01 & 0 & -1.17 \\
\hline & East & -4205.03 & -3706.40 & 0 & -1.25 \\
\hline & Vertical & -6560.94 & -6207.50 & 0 & -1.08 \\
\hline \multirow[t]{3}{*}{ DNGD } & North & -3488.74 & -2910.76 & 0 & -1.58 \\
\hline & East & -3540.64 & -3015.86 & 0 & -1.42 \\
\hline & Vertical & -5044.53 & -4955.38 & 0 & -0.95 \\
\hline \multirow[t]{3}{*}{ DRCL } & North & -3168.75 & -2561.31 & 0 & -1.65 \\
\hline & East & -2929.37 & -2607.21 & 0 & -1.3 \\
\hline & Vertical & -4042.27 & -3911.23 & 0 & -1.17 \\
\hline \multirow[t]{3}{*}{ GNTW } & North & -1674.57 & -1596.75 & 0 & -0.87 \\
\hline & East & -1921.82 & -1696.71 & 0 & -1.19 \\
\hline & Vertical & -3012.66 & -2985.14 & 0 & -0.88 \\
\hline \multirow[t]{3}{*}{ GRHI } & North & -4877.06 & -4049.36 & 0 & -1.36 \\
\hline & East & -4729.85 & -4142.45 & 0 & -1.26 \\
\hline & Vertical & -7579.67 & -6798.90 & 0 & -1.43 \\
\hline JMLA & North & -4325.26 & -3798.01 & 0 & -0.95 \\
\hline & East & -4045.64 & -3592.44 & 0 & -1.31 \\
\hline & Vertical & -6442.01 & -6236.24 & 0 & -0.79 \\
\hline JMSM & North & -5058.51 & -4315.57 & 0 & -0.92 \\
\hline & East & -4942.91 & -4493.34 & 0 & -1.08 \\
\hline & Vertical & -7612.63 & -7144.88 & 0 & -0.98 \\
\hline
\end{tabular}


Table 2. (Continued.)

\begin{tabular}{|c|c|c|c|c|c|}
\hline \multirow[b]{2}{*}{ Site code } & \multirow[b]{2}{*}{ Component } & \multicolumn{2}{|c|}{ Max log-likelihood } & \multirow{2}{*}{$\begin{array}{c}\Lambda \text {-statistic } \\
\text { WPL vs. WN }\end{array}$} & \multirow{2}{*}{$\begin{array}{c}\text { Spectral } \\
\text { index }\end{array}$} \\
\hline & & WN & WPL & & \\
\hline \multirow[t]{3}{*}{ KLDN } & North & -5419.7 & -4621.74 & 0 & -1.23 \\
\hline & East & -5226.17 & -4795.32 & 0 & -1.13 \\
\hline & Vertical & -7986.22 & -7679.17 & 0 & -1.00 \\
\hline \multirow[t]{3}{*}{ NPGJ } & North & -5184.85 & -3758.84 & 0 & -1.65 \\
\hline & East & -4351.5 & -3922.52 & 0 & -1.49 \\
\hline & Vertical & -6603.12 & -6381.82 & 0 & -1.28 \\
\hline \multirow[t]{3}{*}{ SMKT } & North & -3045.39 & -2608.53 & 0 & -1.11 \\
\hline & East & -3128.85 & -2696.85 & 0 & -1.15 \\
\hline & Vertical & -4675.27 & -4452.74 & 0 & -0.85 \\
\hline \multirow[t]{3}{*}{ SRNK } & North & -2849.87 & -2592.56 & 0 & -1.12 \\
\hline & East & -2838.6 & -2624.65 & 0 & -1.3 \\
\hline & Vertical & -4429.8 & -4333.93 & 0 & -0.81 \\
\hline \multirow[t]{3}{*}{ TIMP } & North & -3469.31 & -3249.54 & 0 & -0.9 \\
\hline & East & -3685.8 & -3431.97 & 0 & -0.89 \\
\hline & Vertical & -5945.85 & -5562.08 & 0 & -1.11 \\
\hline
\end{tabular}
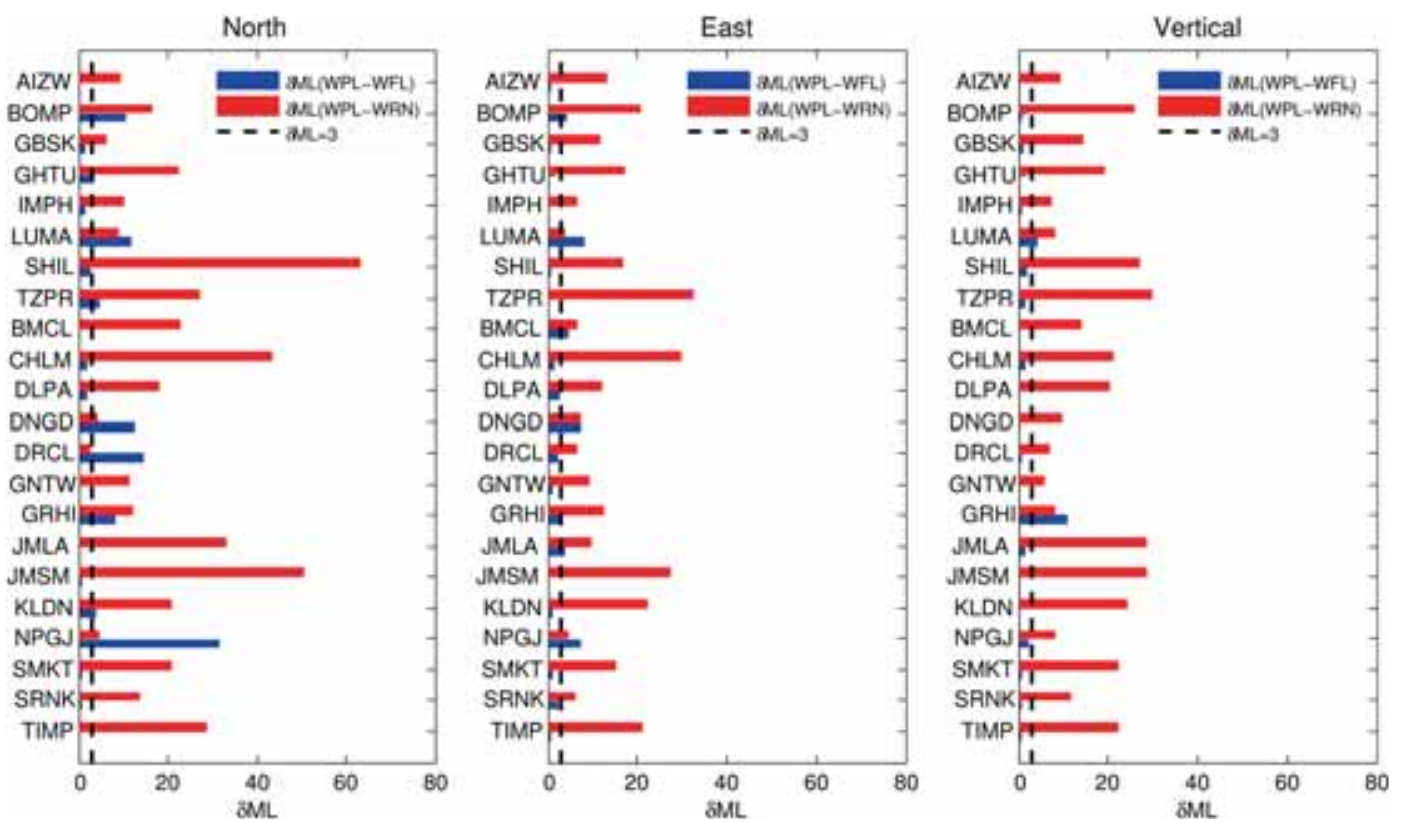

Figure 3. Difference of MLL values for time series. Dashed line represents the rejection criteria. Values below the dashed line depict equal significance of the models and above the line represent superiority of one model relative to other.

for rejecting a lower ranking model. Figure 3 presents the difference between the MLL values of WPL from that of the WFL and WRN models for time series, respectively. The percentage of the superiority of WPL over WRN is $98 \%$. From figure 3 and following the rejection criteria, we found that $\sim 74 \%$ cases where both WPL and WFL are equally acceptable a priori models which suggests that the PL process in those time series is more closer to the FL noise than to the RW noise. As for all of the components, the WPL model is having larger MLE values, so we argue in favour of the WPL model as the most appropriate a priori noise model for this region. However, we found an anomaly that in the case of a Nepal site DRCL, the north component of time series is best described by WRN model. The higher correlated process in DRCL may be due to the mixture of tectonic as well as local site effects. More observations from the regions west of DRCL (i.e., Uttarakhand state of Himalaya), if available in future, may help resolve the cause of this anomaly whether it is associated with nonlinear tectonic deformation or a local effect. 


\subsection{Effect of time-correlated noise on velocity uncertainty}

When the rates are estimated by assuming the noise content to be uncorrelated, the covariance matrix is simplified into a diagonal matrix (Santamaría-Gómez et al. 2011). Earlier studies by Wyatt (1982, 1989), Langbein and Johnson (1997) and Zhang et al. (1997) detected time-correlated noise in the geodetic time series. Mao et al. (1999) observed that if only white noise is assumed, then the velocity uncertainties are underestimated by factors of $5-11$. Upon analysing the global time series, Santamaría-Gómez et al. (2011) observed that the mean vertical velocity uncertainty estimates are 4-5 times larger when data are assumed to be uncorrelated. Later, Wang et al. (2012) found that when the pure white noise model is assumed, velocity uncertainties of GPS sites in China were underestimated by factors of 8-10 when compared to the white plus FL or the PL noise model. In our study, the velocity error estimates of GPS sites in north-east India and Nepal Himalayas when incorporating different noise models based on the MLE are shown in figure 4 . The uncertainties were underestimated by a factor of $\sim 8$ to 14 when the pure white noise model is adopted compared to white plus FL or PL noise. For DRCL, the north component of which is described by WRN, the uncertainties are found to be underestimated by factors of $\sim 10$ and $\sim 13$ in time series, respectively, when the white noise model is used compared to white plus FL or PL noise. The median values of velocity uncertainties of noise models (WN, WPL and WFL) and percentage of uncertainty variation on employing coloured noise models (WPL and WFL) with respect to $\mathrm{WN}$ is provided in table 3 . The assumption of WFL or WPL noise model over the time uncorrelated white noise model shows more than $80 \%$ of increase in horizontal velocity uncertainties (table 3). The results show that though the time correlation process is highly prominent in north-east India and Nepal Himalayas, the temporal correlation is comparatively high, especially in horizontals, in Nepal Himalayas compared to north-east India. However, the time-correlated processes in the verticals are high in north-East India than Nepal Himalaya. This may be due to the large monsoonal hydrological loading over this region.

Considering all temporal correlations, we obtained the following velocities (table 4) for the GPS sites of north-east India and Nepal Himalaya. The velocities represent recent geodynamic rates with most realistic uncertainties. These velocities can be further used for determining various physical interpretations of tectonic motion in the region of north-east India and Nepal Himalaya. Craig and Calais (2014) used the first-order Gauss-Markov extrapolation (FOGMEx) algorithm of Herring (2003) in order to obtain realistic velocity uncertainties. They compared the uncertainties obtained using FOGMEx to those obtained from the MLE
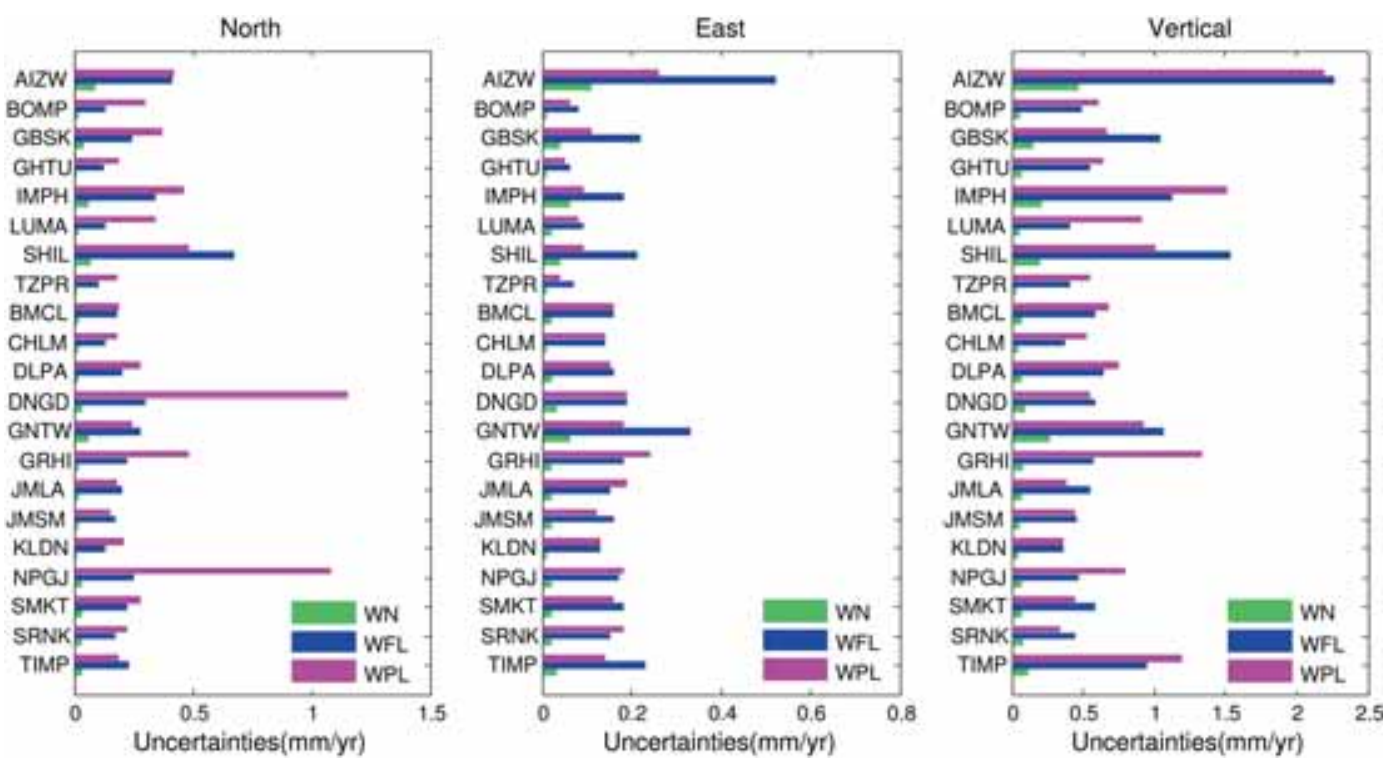

Figure 4. Velocity uncertainties obtained when adopting WN (white noise), WFL and WPL noise models. 
Table 3. Median velocity uncertainties of noise models (WN, WPL and WFL) along with percentage uncertainty variation when the coloured noise model was used.

\begin{tabular}{|c|c|c|c|c|c|}
\hline Component & $\begin{array}{c}\mathrm{WN} \\
(\mathrm{mm} / \mathrm{yr})\end{array}$ & $\begin{array}{c}\text { WFL } \\
(\mathrm{mm} / \mathrm{yr})\end{array}$ & $\begin{array}{c}\text { WPL } \\
(\mathrm{mm} / \mathrm{yr})\end{array}$ & $\begin{array}{c}\% \text { of uncertainty } \\
\text { variation WFL/WN }\end{array}$ & $\begin{array}{c}\% \text { of uncertainty } \\
\text { variation } \mathrm{WPL} / \mathrm{WN}\end{array}$ \\
\hline \multicolumn{6}{|c|}{ North-east India } \\
\hline North & 0.03 & 0.19 & 0.36 & 83.78 & 91.54 \\
\hline East & 0.03 & 0.19 & 0.2 & 83.78 & 84.61 \\
\hline Up & 0.1 & 0.8 & 0.79 & 86.79 & 86.62 \\
\hline \multicolumn{6}{|c|}{ Nepal Himalaya } \\
\hline North & 0.02 & 0.2 & 0.23 & 90 & 91.3 \\
\hline East & 0.02 & 0.19 & 0.32 & 89.19 & 93.65 \\
\hline Up & 0.07 & 0.56 & 0.53 & 87.5 & 86.79 \\
\hline
\end{tabular}

Table 4. Estimates of secular velocities with associated uncertainties adopting the WPL noise model.

\begin{tabular}{|c|c|c|c|c|c|c|}
\hline \multirow[b]{2}{*}{ Site code } & \multicolumn{6}{|c|}{ ITRF08 velocities $(\mathrm{mm} / \mathrm{yr})$} \\
\hline & $N$ & $N \sigma$ & $E$ & $E \sigma$ & $U$ & $U \sigma$ \\
\hline AIZW & 28.64 & 0.42 & 35.38 & 0.44 & -8.21 & 2.19 \\
\hline BOMP & 20.96 & 0.31 & 42.89 & 0.20 & 0.3 & 0.62 \\
\hline GBSK & 27.96 & 0.38 & 40.49 & 0.18 & 3.08 & 0.67 \\
\hline GHTU & 30.26 & 0.19 & 40.55 & 0.10 & 0.86 & 0.65 \\
\hline IMPH & 19.04 & 0.47 & 30.42 & 0.27 & -3.97 & 1.52 \\
\hline LUMA & 22.54 & 0.35 & 38.98 & 0.32 & -0.26 & 0.92 \\
\hline SHIL & 30.85 & 0.48 & 39.46 & 0.19 & -1.59 & 1.00 \\
\hline TZPR & 27.17 & 0.18 & 41.52 & 0.07 & -0.15 & 0.55 \\
\hline BMCL & 33.03 & 0.19 & 35.36 & 0.40 & 1.62 & 0.68 \\
\hline CHLM & 26.78 & 0.18 & 37.23 & 0.20 & 4.62 & 0.52 \\
\hline DLPA & 24.43 & 0.28 & 34.76 & 0.30 & 3.75 & 0.75 \\
\hline DNGD & 34.10 & 1.15 & 37.60 & 0.54 & -1.57 & 0.54 \\
\hline DRCL & 28.65 & 1.99 & 31.49 & 0.64 & 1.59 & 1.02 \\
\hline GNTW & 33.95 & 0.24 & 33.93 & 0.53 & 1.25 & 0.92 \\
\hline GRHI & 33.15 & 0.48 & 37.04 & 0.33 & -0.28 & 1.33 \\
\hline JMLA & 25.55 & 0.18 & 33.69 & 0.34 & 2.55 & 0.38 \\
\hline JMSM & 25.68 & 0.15 & 35.80 & 0.20 & 4.07 & 0.44 \\
\hline KLDN & 34.70 & 0.21 & 36.95 & 0.18 & 1.08 & 0.36 \\
\hline NPGJ & 36.21 & 1.08 & 36.82 & 0.55 & -0.87 & 0.79 \\
\hline SMKT & 21.85 & 0.28 & 32.29 & 0.27 & 3.42 & 0.44 \\
\hline SRNK & 30.95 & 0.22 & 36.68 & 0.30 & 1.40 & 0.33 \\
\hline TIMP & 27.79 & 0.19 & 41.42 & 0.21 & -0.79 & 1.19 \\
\hline LHAZ & 15.4 & 0.08 & 46.34 & 0.07 & 1.4 & 0.3 \\
\hline
\end{tabular}

method of Williams (2008) and observed that in some cases, uncertainties obtained by the FOGMEx method were underestimated, which they realised to be pivotal while describing the lack of detectable deformation in Central Eastern United States. The findings of Craig and Calais (2014) legitimise the use of MLE-based noise models while estimating the uncertainties.
Table 5. Summary of time series groups analysed: Ten different time series lengths have been grouped into four groups of different data periods.

\begin{tabular}{lcccc}
\hline Span & a & b & c & d \\
\hline 10 & $2003-2013$ & - & - & - \\
9 & $2004-2013$ & $2003-2012$ & - & - \\
8 & $2004-2012$ & $2003-2011$ & - & - \\
7 & $2004-2011$ & $2003-2010$ & - & - \\
6 & $2007-2013$ & $2004-2010$ & $2003-2009$ & - \\
5 & $2008-2013$ & $2007-2012$ & $2004-2009$ & $2003-2008$ \\
4 & $2008-2012$ & $2007-2011$ & $2004-2008$ & $2003-2007$ \\
3 & $2008-2011$ & $2007-2010$ & $2004-2007$ & $2003-2006$ \\
2 & $2008-2010$ & $2007-2009$ & $2004-2006$ & $2003-2005$ \\
1 & $2008-2009$ & $2007-2008$ & $2004-2005$ & $2003-2004$ \\
\hline
\end{tabular}

\subsection{Length of time series and velocity uncertainties}

To analyse the effect of the time span of GPS observations on velocity uncertainties and to compute the minimum period of observations required to obtain robust crustal velocities with realistic uncertainties in these regions, we windowed the time series in ascending order of time span, from 1 to $10 \mathrm{yr}$ (table 5). Different periods of the same data span were analysed separately, following Santamaría-Gómez et al. (2011), from the newer group (a) to older (b-d) with an intention to compare the velocity uncertainty of newer data with that of the older one. The uncertainties for each group have been estimated using the WPL model. Figure 5 represents the median of velocity uncertainty of each group. For each group of time series, the uncertainties are found to get reduced significantly with time span. The uncertainties follow a PL with the time span. Table 6 provides the time required to reach a velocity uncertainty of $0.45 \mathrm{~mm} / \mathrm{yr}$ for the groups $(\mathrm{a}-\mathrm{d})$. It is observed from table 5 that 

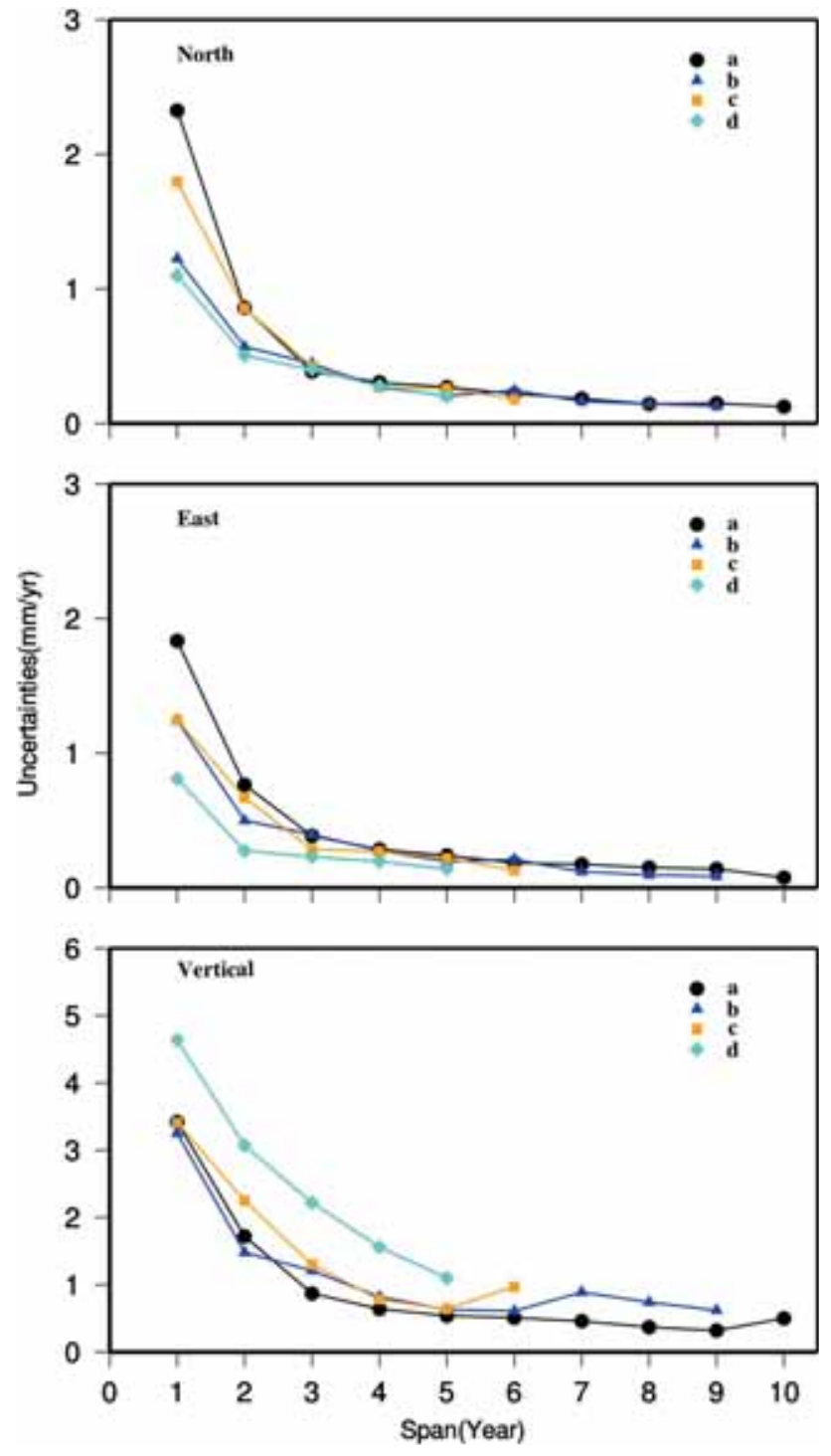

Figure 5. Median velocity uncertainties of data groups (a-d as given in table 4) for three components (north, east and vertical) are given with respect to length of the daily GPS observation in years.

for the horizontal components, the time required to reach mean velocity uncertainties of $0.45 \mathrm{~mm} / \mathrm{yr}$ is more in the newer data (group a) than the older groups $(b-d)$. In contrast, older data groups require more time to reach mean uncertainty in the case of the vertical component. Santamaría-Gómez et al. (2011) mainly concentrated on the vertical component and found that newer data (4a) took $4 \mathrm{yr}$ to achieve an uncertainty level of $0.45 \mathrm{~mm} / \mathrm{yr}$ and older data $(6 \mathrm{~b})$ took $\sim 6 \mathrm{yr}$. We get $\sim 6 \mathrm{yr}$ for newer data to achieve a $0.45 \mathrm{~mm} / \mathrm{yr}$ uncertainty level. The difference between our results and Santamaría-Gómez et al. (2011) is probably due to the difference in the scale of networks considered in both the studies and any unfiltered
Table 6. Time required for the time series of the groups to reach uncertainty of $0.45 \mathrm{~mm} / \mathrm{yr}$.

\begin{tabular}{lccc}
\hline Groups & $\begin{array}{c}\text { North } T_{0.45} \\
(\mathrm{yr})\end{array}$ & $\begin{array}{c}\text { East } T_{0.45} \\
(\mathrm{yr})\end{array}$ & $\begin{array}{c}\text { Vertical } T_{0.45} \\
(\mathrm{yr})\end{array}$ \\
\hline $\mathrm{a}$ & 3.17 & 2.96 & 6.42 \\
$\mathrm{~b}$ & 2.65 & 2.41 & 9.37 \\
$\mathrm{c}$ & 3.07 & 2.5 & 10.53 \\
$\mathrm{~d}$ & 2.42 & 1.6 & 22.21 \\
\hline
\end{tabular}

residuals of seasonal signals associated with highly complex hydrological loading over these regions. Median velocity uncertainties for each data group (table 4) with length of the time series (figure 5) show that there is a large variation in uncertainties which depends on the combination of years (groups $\mathrm{a}-\mathrm{d}$ ) with the same data span of 1 and $2 \mathrm{yr}$. The spread of median uncertainties is very high, in other words, the chances of obtaining uncertainties with good repeatability are very low, irrespective of the data group for a data span of less than 3 years in the case of horizontals. The horizontal velocities are mainly used to quantify the kinematics of tectonic plates, and in turn, it will be used in geophysical models to understand the complex tectonics of these regions. This analysis of the effect of time span on velocity uncertainties reveals that the minimum period of observation required to estimate the horizontal velocities with realistic uncertainty is $3 \mathrm{yr}$, which is close to the recommendation of Craig and Calais (2014) and Blewitt and Lavallée (2002). The minimum observation period required in the case of verticals is inferred as $5 \mathrm{yr}$, although the trend is not as consistent as horizontals. This may also be due to high seasonal loading in these regions and any unfiltered residuals of seasonal signals in the verticals as the vertical component is more sensitive to hydrological loading and tropospheric delay.

\section{Summary and conclusions}

- GPS time series from north-east India, Nepal Himalaya and Bhutan Himalaya were analysed to study the noise characteristics. MLE was used to characterise the underlying noise in the time series.

- MLL ratio test statistic $(\Lambda)$ rejects the null hypothesis of describing the GPS time series by WN in favour of the WPL model. 
- On comparing the log likelihood values of the WPL model with two other special PL noise models WFL and WRN, we observed that $~ 74 \%$ of the time series can be described by both the WPL and WFL models which suggest that the $\mathrm{PL}$ process in those time series is more closer to FL noise than RW noise. The percentage of superiority of WPL over WRN is $98 \%$.

- We observed that the uncertainties get increased by more than $80 \%$ in the horizontals if we use the white plus FL or PL noise model instead of the white noise model. The time correlated noise is found to be comparatively more in the horizontals of Nepal Himalayas than that of north-east India; however, in the vertical component, the time-correlated noise is more in north-east India. More time-correlated processes in the verticals of north-east India may be due to the large hydrological loading induced by monsoonal rain. We provide our estimates of secular velocities and associated uncertainties based on the WPL noise model, which comes out to be the best noise model in our analysis.

- The uncertainties are found to get reduced significantly with the time series span for each group. The analysis of the effect of time span on velocity uncertainties reveals that the minimum period of observation required in these regions to estimate the horizontal velocities with realistic uncertainty is $3 \mathrm{yr}$. However, in the case of the vertical component, the minimum time span required is $5 \mathrm{yr}$.

- Based on the results, we suggest adopting the WPL noise model with a minimum time span of $3 \mathrm{yr}$ for constraining the tectonic velocities (horizontal) of the Himalayas and north-east India.

\section{Acknowledgements}

We acknowledge the grant from the Ministry of Earth Sciences, Govt. of India (MoES/P.O (Seismo)/1(26)/09) for the maintenance of the permanent stations in north-east India. We would like to thank Simon Williams for providing the CATS software. We also thank the Survey of India (SOI), Govt. of India for providing us the data of the permanent GPS stations in Aizawl, Guwahati, Imphal, Sikkim and Shillong. We thank Jean Philippe Avouac and his group at Caltech Tectonics Observatory for establishing, and maintaining the GPS stations in Nepal and opening up the data for public use. We thank Roger Bilham and
Geologic Survey of Bhutan for the Bhutan data. We are profoundly thankful to UNAVCO for making the data publicly available with easily accessible interface to the data archive.

\section{References}

Ader T, Avouac J P, Liu-Zeng J, Lyon-Caen H, Bollinger L, Galetzka J, Genrich J, Thomas M, Chanard K, Sapkota S N and Rajaure S 2012 Convergence rate across the Nepal Himalaya and interseismic coupling on the main Himalayan thrust: Implications for seismic hazard; J. Geophys. Res. 117 B0443, https://doi.org/10.1029/ 2011JB009071.

Agnew D C 1992 The time-domain behavior of power-law noises; Geophys. Res. Lett. 19(4) 333-336.

Altamimi Z, Collilieux X and Métivier L 2011 ITRF2008: An improved solution of the international terrestrial reference frame; J. Geod. 85(8) 457-473.

Argus D F, Peltier W R and Watkins M M 1999 Glacial isostatic adjustment observed using very long baseline interferometry and satellite laser ranging geodesy; J. Geophys. Res. 104(B12) 29,077-29,093.

Amiri-Simkooei A R, Tiberius C C J M and Teunissen S P 2007 Assessment of noise in GPS coordinate time series: Methodology and results; J. Geophys. Res. 112 B07413, https://doi.org/10.1029/2006JB004913.

Banerjee $\mathrm{P}$ and Bürgmann R 2002 Convergence across the northwest Himalaya from GPS measurements; Geophys. Res. Lett. 29(13) 1652, https://doi.org/10.1029/ 2002GL015184

Beavan J 2005 Noise properties of continuous GPS data from concrete pillar geodetic monuments in New Zealand and comparison with data from https://doi.org/10. 1029/2003JB002741 US deep drilled braced monuments; J. Geophys. Res. 110 B084, https://doi.org/10.1029/ 2005JB003642

Bettinelli P, Avouac J P, Flouzat M, Jouanne F, Bollinger L, Willis P and Chitrakar G R 2006 Plate motion of India and interseismic strain in the Nepal Himalaya from GPS and DORIS measurements; J. Geod. 80(8-11) 567-589.

Blewitt G and Lavallée D 2002 Effect of annual signals on geodetic velocity; J. Geophys. Res. 107 2010, https://doi. org/10.1029/2001JB000570

Böhm J, Heinkelmann R and Schuh H 2007 Short note: A global model of pressure and temperature for geodetic applications; J. Geod. 81(10) 679-683.

Cardellach E, Elósegui P and Davis J L 2007 Global distortion of GPS networks associated with satellite antenna model errors; J. Geophys. Res. 112 B07405, https://doi. org/10.1029/2006JB004675

Craig T J and Calais E 2014 Strain accumulation in the New Madrid and Wabash Valley seismic zones from 14 years of continuous GPS observation; J. Geophys. Res. 119. https://doi.org/10.1002/2014JB011498.

Estey L H and Meertens C M 1999 TEQC: The multi-purpose toolkit for GPS/GLONASS data; GPS Solut. 3(1) 42-49. 
Herring T 2003 MATLAB tools for viewing GPS velocities and time series; GPS Solut. 7 194-199. https://doi.org/ 10.1007/s10291-003-0068-0.

Herring T A, King R W and McClusky S C 2010a Documentation of the GAMIT GPS analysis software release 10.4; Department of Earth and Planetary Sciences, Massachusetts Institute of Technology, Cambridge, Massachusetts.

Herring T A, King R W and McClusky S C 2010b GLOBK, global kalman filter VLBI and GPS analysis program, version 10.4; Department of Earth, and Planetary Sciences, Massachusetts Institute of Technology, Cambridge, Massachusetts.

Kendall M and Stuart A 1979 The Advanced Theory of Statistics: Inference and Relationship; 4th edn, Vol. 2, Charles Griffin, London, pp. 240-274.

Kouba J 2008 Implementation and testing of the gridded Vienna Mapping Function 1 (VMF1); J. Geod. 82(4-5) 193-205.

Langbein J 2012 Estimating rate uncertainty with maximum likelihood: Differences between power-law and flickerrandom-walk models; J. Geod. 86(9) 775-783.

Langbein J 2004 Noise in two-color electronic distance meter measurements revisited; J. Geophys. Res. 109 B04406, https://doi.org/10.1029/2003JB002819

Langbein J 2008 Noise in GPS displacement measurements from Southern California and Southern Nevada; J. Geophys. Res. 113 B05405, https://doi.org/10.1029/ 2007JB005247

Langbein J and Johnson H 1997 Correlated errors in geodetic time series: Implications for time-dependent deformation; J. Geophys. Res. 102(B1) 591-603.

Langbein J O, Linker M F, McGarr A F and Slater L E 1987 Precision of two-color geodimeter measurements: Results from 15 months of observations; J. Geophys. Res. 92(B11) 11644-11656.

Lyard F, Lefevre F, Letellier T and Francis O 2006 Modelling the global ocean tides: Modern insights from FES2004; Ocean. Dynam. 56(5-6) 394-415.

Mahesh P, Catherine J K, Gahalaut V K, Kundu B, Ambikapathy A, Bansal A, Premkishore L, Narsaiah M, Ghavri S, Chadha R K, Choudhary P, Singh D K, Singh S K, Kumar S, Nagarajan B, Bhatt B C, Tiwari R P, Kumar A, Kumar A, Bhu H and Kalita A 2012 Rigid Indian plate: Constraints from GPS measurements; Gondwana Res. 22(3) 1068-1072.

Mandelbrot B B and Van Ness J W 1968 Fractional Brownian motions, fractional noises and applications; SIAM Rev. 10(4) 422-437.

Corresponding editor: MunuKutla RADHAKRISHNA
Mao A, Harrison C G and Dixon T H 1999 Noise in GPS coordinate time series; J. Geophys. Res. 104(B2) 27972816.

Ray J D 2016 Noise characteristics of geodetic position time series and analysis of hydrologic deformation of north east India and Nepal Himalaya using GPS and GRACE; PhD Thesis, Tezpur University, Assam, India.

Santamaría-Gómez A, Bouin M N, Collilieux $\mathrm{X}$ and Wöppelmann G 2011 Correlated errors in GPS position time series: Implications for velocity estimates; J. Geophys. Res. 116 B01405, https://doi.org/10.1029/ 2010JB007701

Schaer S, Gurtner W and Feltens J 1998 IONEX: The ionosphere map exchange format version 1; In: Proceedings of the IGS AC Workshop, Darmstadt, Germany (Vol. 9, No. 11).

Steigenberger P, Rothacher M, Fritsche M, Rülke A and Dietrich R 2009 Quality of reprocessed GPS satellite orbits; J. Geod. 83(3-4) 241-248.

Tregoning P and Van Dam T 2005 Atmospheric pressure loading corrections applied to GPS data at the observation level; Geophys. Res. Lett. 32(22) L22310, https://doi.org/ 10.1029/2005GL024104

Wang W, Zhao B, Wang Q and Yang S 2012 Noise analysis of continuous GPS coordinate time series for CMONOC; Adv. Space Res. 49(5) 943-956.

Williams S D 2003 Offsets in global positioning system time series; J. Geophys. Res. 108(B6) 2310. https://doi.org/ 10.1029/2002JB002156

Williams S D 2008 CATS: GPS coordinate time series analysis software; GPS Solut. 12(2) 147-153.

Williams S D and Willis P 2006 Error analysis of weekly station coordinates in the DORIS network; J. Geod. 80(8-11) 525-539.

Williams S D, Bock Y, Fang P, Jamason P, Nikolaidis R M, Prawirodirdjo L, Miller M and Johnson D J 2004 Error analysis of continuous GPS position time series; J. Geophys. Res. 109 B03412, https://doi.org/10.1029/ 2003JB002741

Wyatt F 1982 Displacement of surface monuments: Horizontal motion; J. Geophys. Res. 87 979-989.

Wyatt F 1989 Displacement of surface monuments - Vertical motion; J. Geophys. Res. 94 1655-1664.

Zhang J, Bock Y, Johnson H, Fang P, Williams S, Genrich J, Wdowinski S and Behr J 1997 Southern California permanent GPS geodetic array: Error analysis of daily position estimates and site velocities; J. Geophys. Res. 102(B8) $18,035-18,055$. 